\title{
A phosphate enema-associated chemical colitis
}

\author{
Murat Yildar $^{1 *}$, Murat Basbug ${ }^{1}$, Faruk Cavdar $^{1}$
}

\begin{abstract}
Enemas are widely used in patients with poor colon cleansing in preparation for colonoscopy. Although they are regarded as having minimal side-effects, enemas can give rise to severe side-effects due to the chemical substances they sometimes contain. We report a case of ischemic colitis emerging in association with enema use during preparation for colonoscopy in a 45-year-old woman who was performed rectal resection due to ischemiarelated stricture.
\end{abstract}

Key words: Chemical colitis, Rectal fibrosis, Phosphate Enema, Colonoscopy

\section{Introduction}

Colonoscopy is widely used for the diagnosis and treatment of colonic lesions. Adequate bowel cleansing is the basis of successful colonoscopy ( 1 ). Various preparations are used to preparation for colonoscopy. The most popular of these are polyethylene glycol (PEG) and sodium phosphate, which generally provide adequate cleansing $(\underline{2})$. The use of enemas, the basic element in preparation for colonoscopy until the development of PEG, is today limited to individuals with poor colonoscopy preparation ( $\underline{3})$.

Oral use of drugs including sodium phosphate for colonoscopy preparation may lead to electrolyte anomalies and renal toxicity. Rectal use is reported to lead to complications such as hyperphosphatemia, hypokalemia and, rarely, rectal necrosis $(\underline{2}, \underline{4}, \underline{5})$.

We report a case of chemical colitis in the rectum associated with enema during preparation for colonoscopy performed to investigate the etiology of abdominal pain.

Case

A 45-year-old woman was scheduled for colonoscopy. The patient had long-term abdominal pain, but no history of rectal bleeding. Preparation for colonoscopy was initiated with laxative containing $500 \mathrm{mg}$ sennoside A + B calcium (XM Solüsyon ${ }^{\circledR}$, Yenişehir Pharmaceuticals, Turkey) the preceding day. However, since the patient failed to exhibit sufficient compliance with dietary restriction, enema was administered containing $28.5 \mathrm{~g}$ sodium dihydrogen phosphate and $10.5 \mathrm{~g}$ disodium hydrogen phosphate in $177 \mathrm{ml}$ (BT enema $135 \mathrm{ml}$ ) into the rectum in hospital before colonoscopy. Defecation was occurred post-enema. In the Colonoscopy was revealed widespread petechial lesions and ischemialike appearance in the mucosa, more intense in the distal part of the rectum (Figure 1). Access to the proximal colon was impossible due to severe pain and fragility in the mucosa. During the procedure, Blood pressure was $100 / 70 \mathrm{mmHg}$ and heart rate $106 / \mathrm{min}$. Following the procedure, hospitalization was advised, but the patient, who reported no pain, refused hospitalization, the patient was represented to our clinic 2 months later due to constipation. Anamnesis revealed rectal bleeding with defecation for 1 week after colonoscopy. The rectal ampulla was empty at digital rectal examination, and rectoscopy was performed without enema. Narrowing 4-5 $\mathrm{mm}$ in diameter associated with fibrosis was observed at the $7^{\text {th }} \mathrm{cm}$ in the rectal lumen (Figure 2). Surgery was recommended. Low anterior resection was performed at another center, and were reported submucosal fibrosis and mucosal erosion in pathologic examination

\section{Discussion}

Enema was represented the basic component of colonoscopy preparation until the development of PEG by Davis et al. in $1980(\underline{3}, \underline{6})$. In 1992, Lever et al. suggested that additional use of enemas following colonoscopy preparation with PEG was not useful and increased patient discomfort (ㄱ) . 


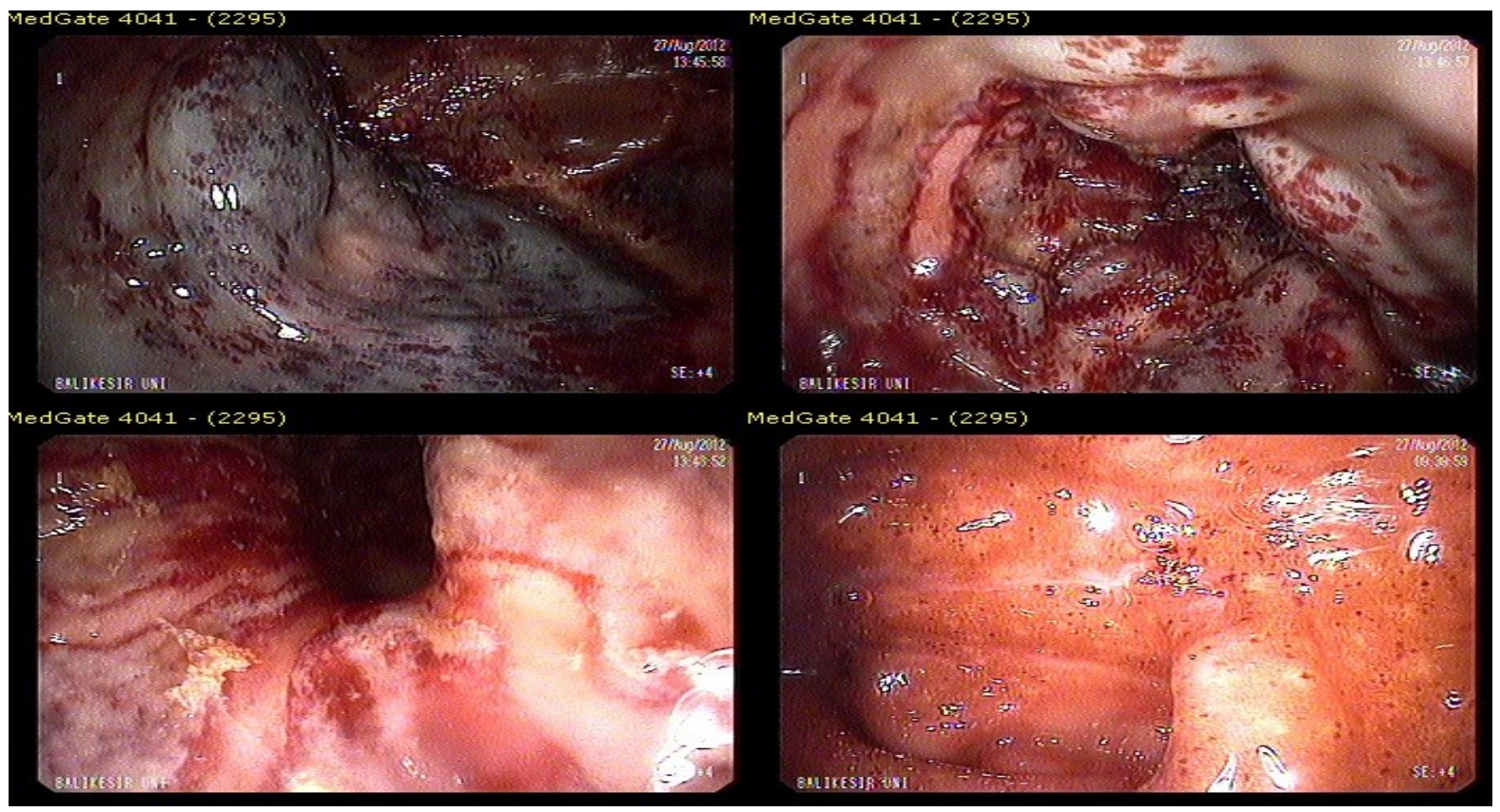

Figure 1: Widespread petechial lesions and ischemia-like appearance in the rectal mucosa

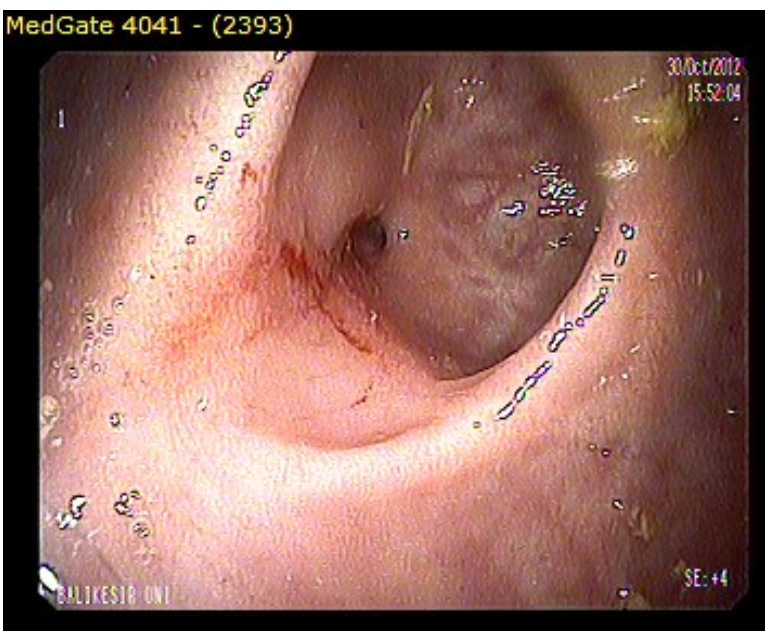

Figure 2: Narrowing due to fibrosis in the rectal lumen

On the basis of this anecdotal information, the American Society for Gastrointestinal Endoscopy (ASGE) recommended the use of enema in individuals with poor distal colon preparation ( $\underline{3})$.

Various enema preparates containing water, soap foam, mineral fats, hydrogen peroxide, bisacodyl or sodium phosphate are available (으). Although they have been used in the general population with minimal side-effects for years, enemas can sometimes cause severe side-effects ( $(7)$. Life-threatening colitis developing in association with hydrogen peroxide have been reported (ㅇ). Side-effects such as hyperphosphatemia, hyponatremia, hypocalcemia, hypokalemia and metabolic acidosis have been reported in association with enemas containing sodium phosphate. These side-effects have particularly been reported in advanced age groups and in individuals with comorbid diseases such as kidney failure (9). Cases of rectal necrosis requiring abdominoperineal resection and permanent colostomy have been reported following phosphate enema use (). Authors suggested that the necrosis is started by mechanic injury of the rectum by the tip of the enema tube (ㄷ). In our patient, Colitis was generalized and traumatic signs were not seen in colonoscopy

Following administration of enema in our case, widespread petechiae and a dark purple appearance resembling ischemia were observed in the rectal mucosa. This colonoscopic appearance resembled a case of colitis mimicking ischemic colitis emerging after administration of enema containing alcohol described by Randolph et al. ( $\underline{10})$. In our patient, enema containing sodium phosphate was used.

Complications such as stricture, perforation and fulminant colitis may develop in cases of chemical colitis due to enema.

Administration of high-dose intravenous steroid and antibiotic therapy has been described in order to prevent these complications (11). Unfortunately, no treatment was performed in the acute period in our case due to patient refusal. However, no septic complications developed. Stricture was developed in the long term, and surgical resection had to be performed.

\section{Conclusion}

In conclusion, enemas used in patients presenting to the emergency department with constipation and to prepare for colonoscopy may lead to such severe complications as chemical colitis and rectal necrosis. Patients scheduled for enema must be informed of potentially life-threatening complications, and the procedure needs to be used in an appropriate patient population in order to minimize enema-related complications 


\section{References}

1. Kao D, Lalor E, Sandha G, Fedorak RN, van der Knoop B, Doornweerd S, et al. A randomized controlled trial of four precolonoscopy bowel cleansing regimens. Canadian journal of gastroenterology $=$ Journal canadien de gastroenterologie. 2011 Dec;25(12):657-62. PubMed PMID: 22175055. PMCID: 3266156. Epub 2011/12/17. eng.

2. Beck DE. Bowel preparation for colonoscopy. Clinics in colon and rectal surgery. 2010 Feb;23(1):10-3. PubMed PMID: 21286285. PMCID: 2850161. Epub 2011/02/03. eng.

3. Wexner SD, Beck DE, Baron TH, Fanelli RD, Hyman N, Shen $\mathrm{B}$, et al. A consensus document on bowel preparation before colonoscopy: prepared by a task force from the American Society of Colon and Rectal Surgeons (ASCRS), the American Society for Gastrointestinal Endoscopy (ASGE), and the Society of American Gastrointestinal and Endoscopic Surgeons (SAGES). Gastrointestina endoscopy. 2006 Jun;63(7):894-909. PubMed PMID 16733101. Epub 2006/05/31. eng.

4. Davis RF, Eichner JM, Bleyer WA, Okamoto G. Hypocalcemia, hyperphosphatemia, and dehydration following a single hypertonic phosphate enema. The Journal of pediatrics. 1977 Mar;90(3):484-5. PubMed PMID: 839346. Epub 1977/03/01. eng.

5. Smith I, Carr N, Corrado OJ, Young A. Rectal necrosis after a phosphate enema. Age and ageing. 1987 Sep;16(5):328-30. PubMed PMID: 3687574. Epub 1987/09/01. eng.
6.

Davis GR, Santa Ana CA, Morawski SG, Fordtran JS. Development of a lavage solution associated with minimal water and electrolyte absorption or secretion. Gastroenterology. 1980 May;78(5 Pt 1):991-5. PubMed PMID: 7380204. Epub 1980/05/01. eng.

7. Lever EL, Walter MH, Condon SC, Balasubramaniam K, Chen YK, Mitchell RD, et al. Addition of enemas to oral lavage preparation for colonoscopy is not necessary. Gastrointestinal endoscopy. 1992 May-Jun;38(3):369-72. PubMed PMID: 1607091. Epub 1992/05/01. eng.

8. Kibria R, Ali SA, Barde CJ. Gone but not forgotten. "Bubble gum enema" containing hydrogen peroxide and causing life-threatening colitis. Gastrointestinal endoscopy. 2010 Sep;72(3):619-21. PubMed PMID: 20541200. Epub 2010/06/15. eng.

9. Mendoza J, Legido J, Rubio S, Gisbert JP. Systematic review: the adverse effects of sodium phosphate enema. Alimentary pharmacology \& therapeutics. 2007 Jul 1;26(1):9-20. PubMed PMID: 17555417. Epub 2007/06/09. eng.

10. Randolph M, Longacre TA, Gerson LB. Acute colitis secondary to self-administered alcohol enemas: a mimic of ischemic colitis. Journal of clinical gastroenterology. 2005 Jan;39(1):78-9. PubMed PMID: 15599218. Epub 2004/12/16. eng.

11. Sheibani S, Gerson LB. Chemical colitis. Journal of clinical gastroenterology. 2008 Feb;42(2):115-21. PubMed PMID: 18209577. Epub 2008/01/23. eng.

Copyright (C) 2014 The Author(s); This is an open-access article distributed under the terms of the Creative Commons Attribution License (http://creativecommons.org/licenses/by/4.0), which permits unrestricted use, distribution, and reproduction in any medium, provided the original work is properly cited. 